ISSN 1991- 8690

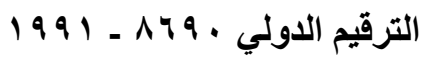

Website: http://jsci.utq.edu.iq

Email: utjsci@utq.edu.iq

\title{
Dielectric Permittivity, Loss Factor and Ac. Conductivity of (Epoxy / Ferrous Sulfide) Composites.
}

\author{
${ }^{1}$ Waleed. A. Hussain \\ ${ }^{2}$ Mohammad T. Obied
}

${ }^{2}$ Abdullah A. Hussein

${ }^{1}$ Hassan K. Ibrahem

\author{
${ }^{1}$ Department of Physics_ College of Education for Pure Sciences. Basra University \\ ${ }^{2}$ Department of Material Science. Polymer Research Centre_University of Basra/ Iraq
}

\begin{abstract}
$\underline{\text { Abstract }}$
The dielectric properties of (Epoxy/Ferrous sulfide) composites were characterized as a function of Ferrous sulfide weight fraction, temperature was in the range $30-150{ }^{\circ} \mathrm{C}$, and frequency was in range $120 \mathrm{~Hz}-2 \mathrm{MHz}$. The dielectric parameters have been measured using parallel plate capacitor method. Experimental results showed that the real $\varepsilon^{\prime}$ and imaginary $\varepsilon^{\prime \prime}$ parts of permittivity increases as Ferrous sulfide weight fraction increases. The values of $\varepsilon^{\prime}$ increase as the temperature increases, the increase was accompanied by the presence of obvious peaks at high temperature which may be related to the increased mobility of segments of epoxy molecules at elevated temperatures below the glass-transition temperature and the differential thermal expansion of the polymer and the filler. The values of $\varepsilon^{\prime}$ decrease as frequency increases, which indicates that the major contribution to polarization is related to orientation polarization. Dielectric loss showed an increase both with an increase in frequency and temperature, loss peaks were observed at $10 \mathrm{kHz}$ and at high temperatures respectively. A.c conductivity and impedance behaviors of the composites as a function of temperature and frequency were investigated too.
\end{abstract}

\section{دراسة الخواص العازلية لمتراكب (راتتج الايبوكسي ـ كبريتيد الدديد)}

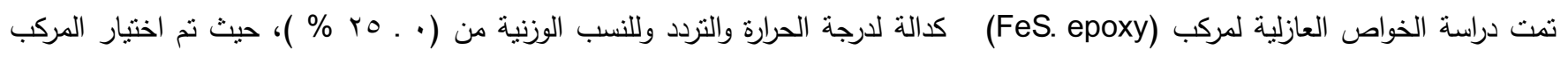
المحضر بسبب امتلاكه خواص عازلية جيدة. مزجت مكونات منراكب ( FeS . epoxy) ، ومن ثم صب المركب الناتج في قوالب مناسبة. بعد ذلك عولج

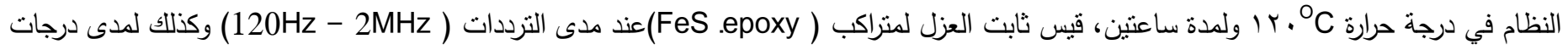

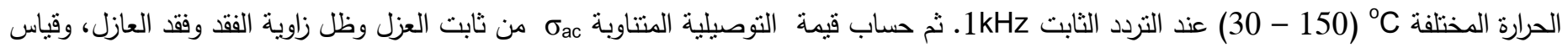

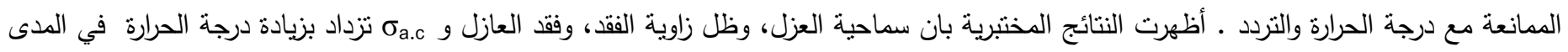
C C (150 - 30) ، كذلك تزداد بزيادة محتوى الحشوة ومع نقصان التزدد. تتناقص الممانعة مع زيادة نسبة الحشوة والتردد ودرجة الحرارة .

\section{Introduction}

The development of electronic devices working at high frequencies, such as fast computers, cellular phones, etc., requires new high dielectric permittivity materials that combine good dielectric properties with both mechanical strength and ease of processing. In particular, the high dielectric permittivity materials are required for making embedded capacitors for integrated electronic devices $[1,2]$.

Dielectric behavior depends on the polarization that is induced in the material due to the effect of an external 
electrical stress. Dielectric spectroscopy can provide useful information on the electrical properties of the specimens. Moreover, this technique can be used as analytical tool whereby the dielectric data is related to other properties such as the polymer molecule structure, morphology, degradation and aging [2].Polymer composite is one of the major subjects in polymer industry. The purpose of alloying or compositing one polymer system with another polymer is to gain synergistic improvement in properties at both the micro and macro levels. Polymeric insulating materials such as epoxy and polyethylene are widely used in manufacturing of weather shade of outdoor insulator and cable terminators [3-6]. Epoxy resins are widely used as suitable matrices besides other applications in modern technology, because they offer versatility, low shrinkage, chemical resistance, relatively low dielectric constant and outstanding adhesion [7]. Epoxy composites are very popular insulators in high voltage engineering, such as Epoxy/Mica composite which is used for insulation in power transformers, station and line posts, insulation of coils in rotating machines, etc. [8]. The determination of the dielectric properties of blended materials and composites is very necessary for finding its appropriate technological applications $[9,10]$. In the present study, epoxy as a matrix and ferrous sulfide (FeS) powder as filler were used to prepare epoxy/FeS composites. The dielectric properties of the prepared composites as a function of filler contents, temperatures, and frequency in addition to impedance have been investigated.

\section{Experimentals}

\subsection{Materials and sample preparation :}

Epoxy resin with the following specification $(\mathrm{Mw}=$ $624 \mathrm{gm} \mathrm{/} \mathrm{mole,} \mathrm{density}=1.27 \mathrm{gm} / \mathrm{cm}^{3}$ ), and a Triethylenetetramine (TETA), supplied by United Chemical Company Ltd., (UNICHEM, JORDEN) was used as hardener. Ferrous sulfide $(\mathrm{FeS})$ powder with $99.9 \%$, density $=4.84 \mathrm{gm} / \mathrm{cm}^{3}$ and average particle size used $25 \mu \mathrm{m}$. FeS supplied by (ALFA PRODUCTS Germany.) was used as filler. Different (epoxy / ferrous sulfide) composites based on filler weight fraction were prepared by mixing appropriate amounts of $\mathrm{FeS}$ powder and Epoxy at about $70^{\circ} \mathrm{C}$ for 5 minutes, then curing agent triethylene tetra amine (TETA) as a hardener was added and mixed for 5 minutes also. The initial curing was carried at room temperature for 24 hours, followed by post curing at $120 \mathrm{oC}$ for 2 hours. Disk shape sandwiches $\mathrm{Al} /$ composite's thick film/Al of diameter (6 $\mathrm{mm}$ ) were prepared for all measurements.

\subsection{Measurements :}

The samples capacitance $\mathrm{C}$ and the loss tangent ( $\tan \delta)$ of the composites were measured by digital RCL bridge type (MEGGER B131), at $120 \mathrm{~Hz}$ and $1 \mathrm{kHz}$. At continuous frequencies in the range $(50 \mathrm{~Hz}-1 \mathrm{MHz})$ RCL type (Programmable automatic RCL meter, FLUKE PM6306) was used to measure the capacitance of the samples. Impedance $\mathrm{Z}$ at different frequencies up to $500 \mathrm{kHz}$ were measured by RCL bridge type ( $\boldsymbol{h} \boldsymbol{p}$ A4800). Dielectric response is generally described by complex permittivity $\varepsilon^{*}=\varepsilon^{\prime}-\mathrm{i} \varepsilon^{\prime \prime}$, where the real part $\left(\varepsilon^{\prime}\right)$ relative permittivity (dielectric constant) and the imaginary part $\left(\varepsilon^{\prime \prime}\right)$ (dielectric loss) components are the storage and loss of energy in each cycle of applied electric field. Relative permittivity (permittivity) $\left(\varepsilon^{\prime}\right)$ was obtained from capacitance data according to the equation [11];

$$
\mathrm{C}=\varepsilon_{\mathrm{o}} \varepsilon^{\prime} \mathrm{A} / \mathrm{d}
$$

where $\mathrm{C}, \varepsilon_{0}, \mathrm{~A}$, and $\mathrm{d}$ represents the capacitance of the material in farad, permittivity of vacuum $\left(8.845 \times 10^{-12}\right.$ $\mathrm{F} / \mathrm{m})$, area of the capacitor plate in $\left(\mathrm{m}^{2}\right)$, and thickness of the material in $(\mathrm{m})$ respectively. The dielectric loss $(\varepsilon ")$ was obtained from permittivity and loss tangent $(\tan \delta)$ values:

$$
\varepsilon^{\prime \prime}=\varepsilon^{\prime} \tan \delta
$$

A.C. conductivity ( $\sigma a . c)$ is calculated according to relation[12].

$$
\sigma \mathrm{a} . \mathrm{c}=\varepsilon \circ \omega \varepsilon^{\prime \prime}
$$

or, $\quad \sigma a . c=\varepsilon \circ \omega \varepsilon^{\prime} \tan \delta$

where, $\omega$ is the angular frequency of applied electric field.

\section{Results and Discussions}

The permittivity $\varepsilon^{\prime}$ of pure epoxy resin and epoxy/FeS composites as a function of $\mathrm{FeS}$ weight fraction at $120 \mathrm{~Hz}$ and $1 \mathrm{kHz}$ is shown in Fig.(1). The increases in $\varepsilon^{\prime}$ with both increase in $\mathrm{FeS}$ content and lower frequency $(120 \mathrm{~Hz})$ are attributed to interfacial polarization/ or Maxwell-Wagner Sillars (MWS) polarization, appears in heterophase systems $[13,14]$. As filler content increases the a opportunity that, clusters of filler particle formation increase and interfacial surfaces increase leading to an increase in interfacial polarization and $\varepsilon^{\prime}$. 


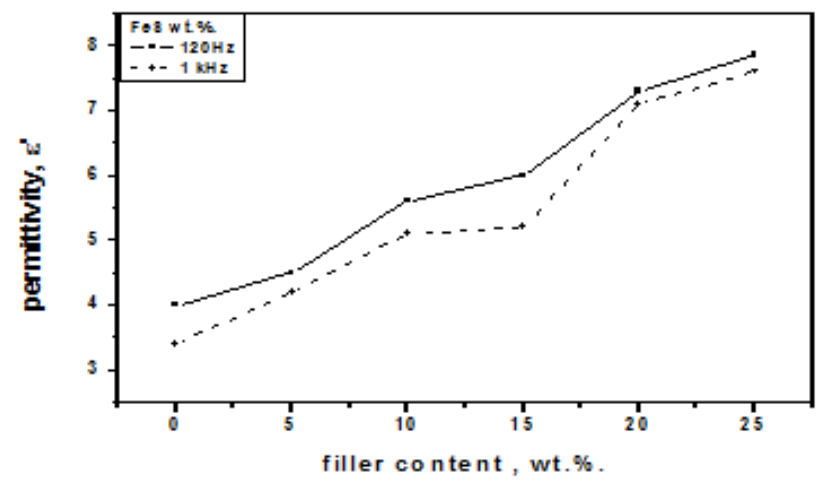

Fig. (1) Variation of composites permittivity as a function of $\mathrm{FeS}$ content at the frequencies $120 \mathrm{~Hz}$ and $1 \mathrm{kHz}$

The permittivity $\varepsilon^{\prime}$ as a function of temperature in the range $30-150{ }^{\circ} \mathrm{C}$, for different $\mathrm{FeS}$ weight fraction composites are depicted in Fig. (2). It can be seen that there is a gradual increases in $\varepsilon^{\prime}$ with the increase in temperature until it reaches a peak point after which $\varepsilon^{\prime}$ decreases gradually with further increase in temperature. This may be related to two competing effects; $1^{\text {st }}$ the increase in segmental mobility of dipoles at elevated temperatures below the glass-transition temperature $\left(\mathrm{T}_{\mathrm{g})}\right.$ in the epoxy matrix (i.e. greater freedom of movement of dipole molecular chain of epoxy at elevated temperature below $T_{g}$ ), $2^{\text {nd }}$ the differential thermal expansion of epoxy and filler which may disrupt the cluster's size of filler which in turn leads to decrease $\varepsilon^{\prime}[15,16]$.

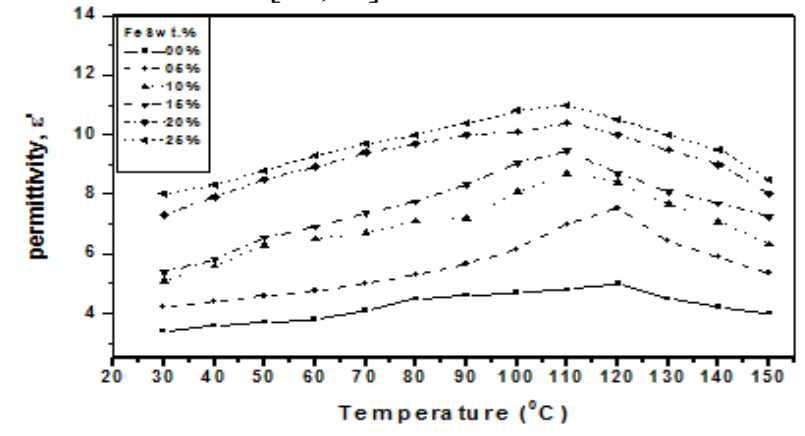

Fig. (2) FeS-epoxy composite permittivity as a function of filler content and temperature

Fig. (3) shows the dependence of $\varepsilon^{\prime}$ of composites on frequency in range $120 \mathrm{~Hz}-2 \mathrm{MHz}$ for different weight fractions of $\mathrm{FeS}$ at room temperature. It is obvious that $\varepsilon^{\prime}$ decreases with an increase of the applied electric field frequency, which indicates that the major contribution to polarization is related to orientation polarization.
This is natural behaviour for heterophase systems that originate from the fact that space charge, interfacial and dipolar polarizations (which have dominant contribution to permittivity at low frequencies) have less time to be oriented with the direction of alternating field as frequency increases. For frequencies higher than $100 \mathrm{kHz}$ atomic and electronic polarization are less affected by the increasing frequency $[17,18]$.

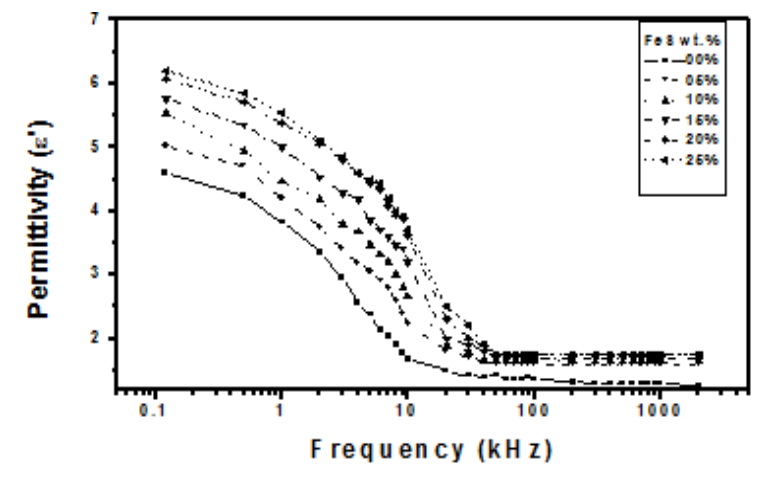

Fig. (3) Frequency and filler content dependence of dielectric permittivity for epoxy/FeS composites

Fig. (4) shows the variation of dielectric loss $\varepsilon "$ as a function of temperature for different $\mathrm{FeS}$ weight fraction epoxy/FeS composites at fixed frequency (1 $\mathrm{kHz}$ ). In general $\varepsilon^{\prime \prime}$ increases as $\mathrm{FeS}$ content and temperature increase. The increase may be attributed to the interfacial polarization and the dipole molecules tendency or parts of dipole molecules to rotate along with the electric field overcoming the forces of internal friction of either the intermolecular interaction or the molecular friction, resulting in the expenditure of a part of electric energy and its conversion into thermal energy, respectively $[12,19]$.

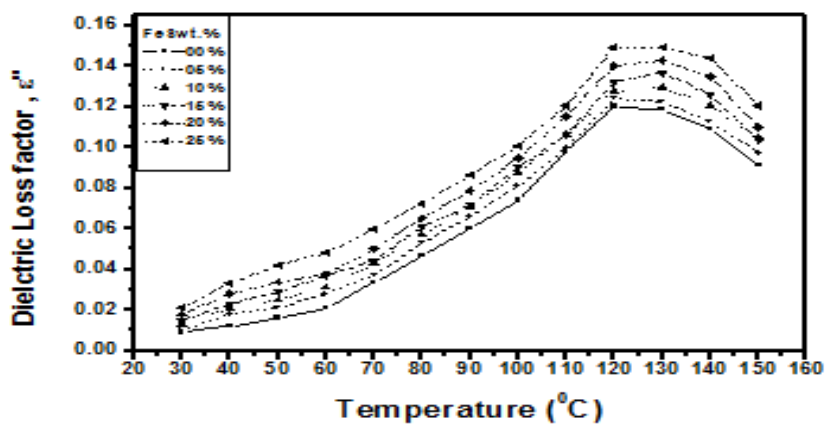

Fig. (4) Temperature and filler content dependence of dielectric loss factor for epoxy/FeS composites 
Fig. (5) shows the variation of dielectric loss $\varepsilon^{\prime \prime}$ with frequency in the range $(120 \mathrm{~Hz}-2 \mathrm{MHz})$ at room temperatures for all samples. This kind of frequency dependency is called dielectric relaxation, being characterized by a relaxation time $\tau$ or relaxation frequency $\mathrm{f}_{\mathrm{o}}$ corresponding to $\Delta \varepsilon / 2$. This relaxations shift to lower frequencies with increasing of Ferrous sulfide content. It can be observed that, values of dielectric loss increase gradually with increasing frequency up to a peak value. This peak is related to the glass transition relaxation of epoxy resin and is denoted as $\square \alpha \square$ relaxation [20]. The increases in dielectric loss may be related to a.c conductivity $\left(\sigma_{\mathrm{ac}}\right)$ which depends on the number of charge carriers, relaxation time and frequency domain when the temperature is constant after that, dielectric loss decrease gradually, due to the relaxation processes which are influenced by the interfacial polarization effect $[21,22]$.

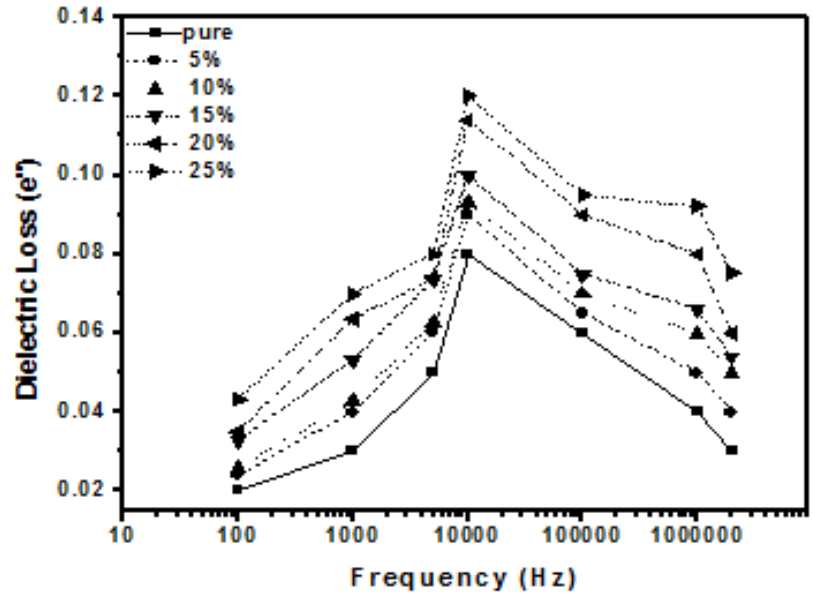

Fig.(5) The dielectric loss as a function of filler content and frequency for epoxy/FeS composites

The relation between relaxation time $\tau$ and $\mathrm{FeS}$ content is shown in Fig. (6). It is obvious that the relaxation time increases with increasing filler content. The increases in $\tau$ with increase in filler content may relate to the increase in a.c conductivity and is attributed to Maxwell-Wagner Sillars (MWS)/ or interfacial polarization appears in complex system exhibiting electrical heterogeneity, due to the accumulation of charges at the interfacial of the system [23].

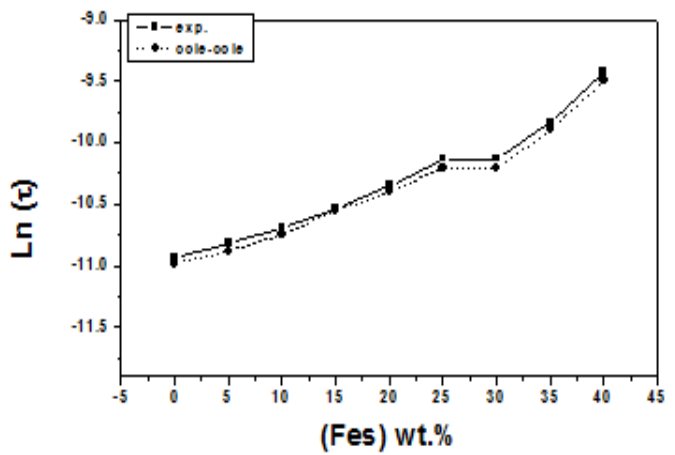

Fig. (6) The relaxation time as a function of filler content for epoxy / FeS composites

The relation between the dielectric loss $\varepsilon^{\prime \prime}$ and dielectric permittivity $\varepsilon^{\prime}$ for epoxy/FeS composites at room temperature is shown in Fig. (7). From the Cole-Cole plot, the generalized relaxation time, the parameter relating to the distribution of relaxation times is determined.

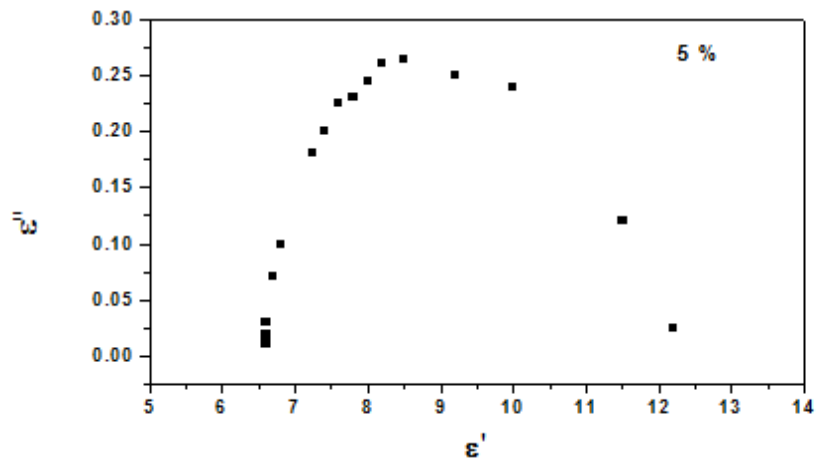

Fig. (7) $\varepsilon^{\prime \prime}$ versus $\varepsilon^{\prime}$ (Cole-Cole plot) for epoxy / FeS composite $5 \%$ wt FeS

Temperature dependence of a.c conductivity for different filler content epoxy / FeS Composites is depicted in Fig. (8). It can be seen that $\sigma_{\mathrm{ac}}$ increases with both $\mathrm{FeS}$ content increases and the temperature rise. This increase may be related to increment in free charge carriers available in the composite system. It was also found that, at higher temperature, high mobility of free charges makes them more frequency independent conductivity [24,25]. The dependence of calculated a.c conductivity on frequency in the range $(120 \mathrm{~Hz}-2 \mathrm{MHz})$ for different weight fraction of FeS at room temperature is shown in Fig. (9). It increased when the filler content increased for all frequency range studied. This increase in a.c conductivity is expected, since at higher applied field frequency more ions and 
impurities are moved. The observed enhancement in a.c conductivity are attributed to ionic interactions and

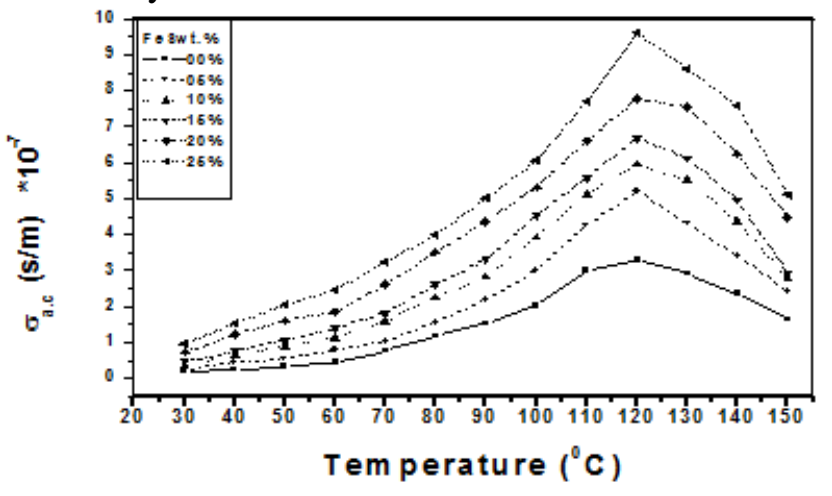

Fig.(8) Temperature dependence of $\sigma_{\mathrm{ac}}$ for different filler content epoxy / FeS Composites

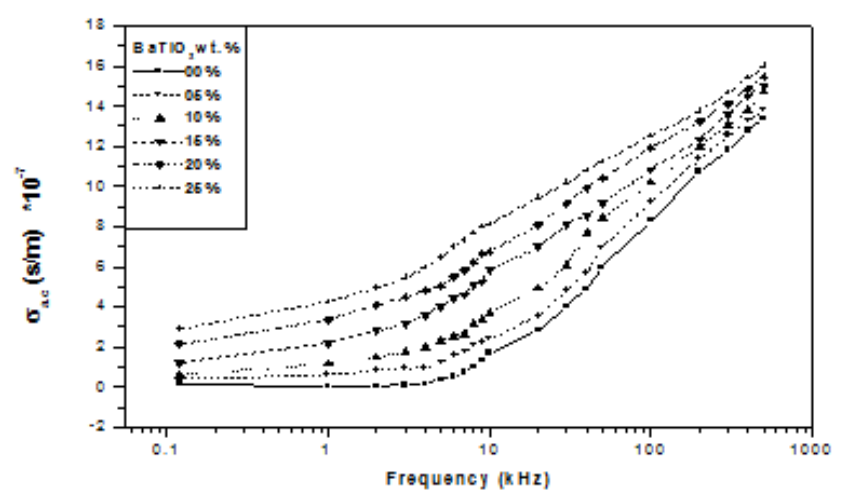

Fig.(9) Frequency dependence of $\sigma_{\mathrm{ac}}$ for different filler content epoxy / FeS Composites

impurity motion taking in the bulk of electrolyte polymer composite [26].Figure (10) Shows the impedance $\mathrm{Z}$ (real component) temperature dependence for pure epoxy and epoxy/ FeS composites (different wt $\%$ ). There is an obvious decrease in $\mathrm{Z}$, with the increasing of filler content due to the increased interfacial polarization, or with the rise in temperature due to increased segmental mobility. Figure (11) Shows the variation of impedance $\mathrm{Z}$ with frequency for epoxy/ FeS composites. It was noticed that the phase angle was always negative, indicating that the composites were capacitive and could be represented by parallel RC networks (lumped circuit) connected in series. As can be seen, there is an exponential decrease in the impedance with the increase in frequency for all filler weight fractions, and the decrease is greater for highly filled composites. Impedance values decrease with increasing frequency or increasing FeS concentration. The observed decrease in impedance with increased $\mathrm{FeS}$ contents is due to the protonic migration transporting and impurities existing in FeS content. This motion leads to higher electrical conduction in the composite [27].

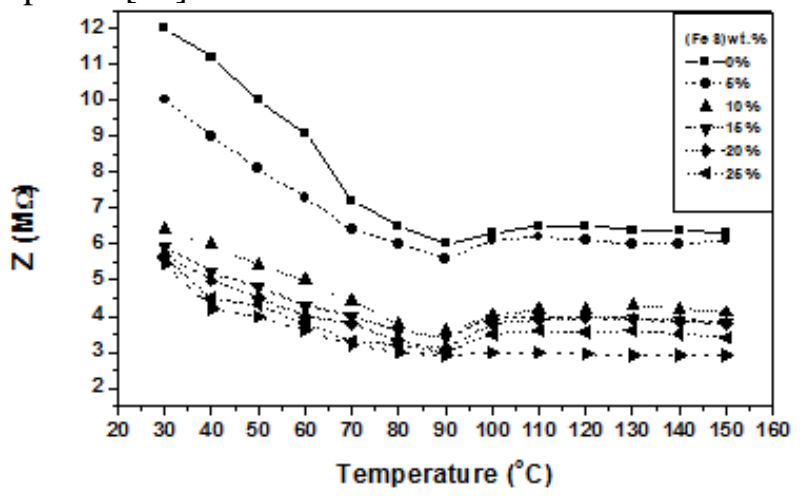

Fig.(10) Impedance of epoxy / FeS composites as a function temperature

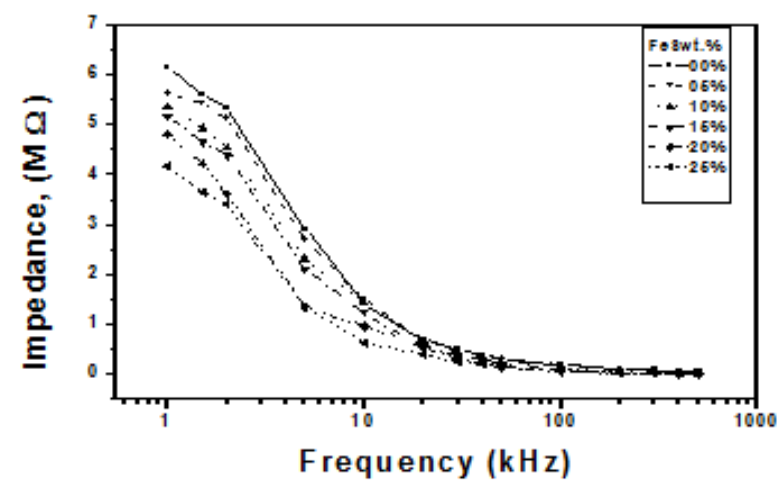

Fig.( 11) Frequency dependence of impedance for different filler content epoxy / FeS Composites

\section{Conclusions}

Dielectric properties (epoxy / FeS) composites have been investigated. It is found that permittivity $\varepsilon^{\prime}$, dielectric loss $\varepsilon^{\prime \prime}$ and a.c conductivity $\sigma_{\mathrm{ac}}$ for all composites increase with increasing the $\mathrm{FeS}$ filler content, or temperature. The permittivity decreases with the increasing of frequency. The impedance $\mathrm{Z}$ of the composites decreases with the increase of filler volume content, frequency and temperature. 


\section{References}

1- R. Popielarz, C.K.Chiang, R.Zozaki and J.Obrzut, J. of Am. Chem. Soc., 34, 5910-5915,(2001).

2- G. G. Raju, Dielectric in Electric Field, Marcel Dekker, Inc,USA, (2003).

3- A. Manzur, R. Olayo, E. Ramos, J Appl Polym Sci, 65, 4, 677-683, (1998).

4- D. Bielinski, A. Wlochowicz, J. Dryzek, C. Slusarczyk, Compos Interf, 8, 1-17, (2001).

5- E. M Sadek, D. E El-Nashar, A. M Motawie, PolymPlast Technol Eng, 42, 627-642, 2003.

6- R. Irinislimane, N. Belhaneche-Bensemra, A. Benlefki, J Polym Environ, 15, 119-124, (2007).

7- G.M. Tsangaris, N.Kouloumbi, S.Kyvelidis, J. Mater. Chem \& Phys., 44, 245- 250, (1996).

8- P. Gonon, T.P. Hong, O. Lesaint, S. Bourdelais and H. Debruyne, Poly. Test., 24, 799-804, (2005).

9- L.A. Ramajo, M.Reboredo, D.Santiago and M.Catro, J. compos. Mater.,42 (2008).

10- A. A. Hussien, Ms.C. Thesis, University of Basra, Basra, Iraq, (2010).

11-V. Singh, A.R. Kulkarni and T.R. Ramamohan, J. Appl. Poly. Sci., 90, 3602-3608, (2003).

12- L. Ramajo, M. Catro and M. Reboredo, J. Appl. Sci. Manuf., 38, 1852-1959, (2007).

13- S. K. Bhattacharya, R. R. Tummala, J. Mater. Sci.: Mater. Electron, 11, 253 (2000)

14- H. J. Park, S.M. Hong, S.S. Lee and M. Park, IEEE Trans. Adv. Pack., 31, (2008).

15- V. Singh, A. R. Kulkarni, T. R. Rama Mohan, Journal of Applied Polymer Science, 90, 36023608 (2003).

16- S. Sindhu, M.R. Anantharaman, B.P. Thampi, K.A. Malini and P. Kurian, Bull.mater. Sci. 25, 599 (2002)

17- B. Tareev. Physics of dielectric materials, Mir puplication Moscow (1975).

18-R. Coelho, Physics of dielectrics for engineer, Elsevier New York (1979).

19- P.G. Babaevsky, N.A. Kozlov, I.V. Churilo, and V.V. Slagoda, Cosmic Research, 43, 1 (2005) 25.

20- A. Linares, A. Nogales, D. R. Rueda, T. A. Ezquerra, Journal of Polymer Science,Part B: Polymer Physics, 45, 1653-1661 (2007).

21-G.C. Psarras, E . Manolakaki and G.M. Tsangaris, Composite part A, 375 (2002).

22- P. Gonon, A. Sylvester, J. Teysseyre and C. Prior, J. Mater. Sci: Materials in Electronics.,12, 81, (2001).
23- E. Şentürk, Crystal Research and Technology, 39, No. 2, 157 - 160 (2004).

24- D. K. Pradhan, R.N.P. Choundhary, B.K. Samantaray, Int. J. Electro. Sci, 3, 597-608, (2008).

25- S.A. Saq'an, A.S. Ayesh, A.M. Zihlif, E. Martuscelli and G. Ragosta, Polym.Test., 23, 739745, (2004).

26- N.Chand and D. Jain, "Bull. Mater. Sci.", 27, 227233, (2004).

27- W. A. Hussain, Ph.D. Thesis, University of Basra, Basra, Iraq, (2006). 